\section{Policies of dental journals for reporting and monitoring authorship and contributorship}

C. M. Faggion $\mathrm{Jr}^{1}$
IN BRIEF

- Informs the readers that a detailed reporting of authorship/contributorship is needed to improve transparency in dental research.

- Highlights that current guidelines for authorship in high-ranked dental journals are not reported in detail to the public.

- Suggests that dental journals should develop strategies to improve author adherence to current guidelines for authorship and contributorship.

Authorship contribution is an important issue that has been discussed frequently in the medical literature. There are many reported cases of 'guest' authors (who sign as authors without meeting authorship criteria) and 'ghost' authors (who are credited to get authorship, but for some reason do not sign the article). Therefore, clear and transparent policies for reporting authorship/contributorship are needed in scientific journals. The objective of this survey was to assess the authorship and contributorship policies that are made publically available on the homepages of dental journals. The policies of 64 impact factor-ranked dental journals were assessed with a 6-item checklist based on the International Committee of Medical Journal Editors (ICMJE) guidelines for authorship/contributorship. Most dental journals partially reported the ICMJE guidelines, and therefore the improvement of this reporting is a requirement to promote transparency and integrity in dental research. Moreover, dental journals should develop strategies to improve author adherence to available guidelines for authorship and contributorship.

\section{INTRODUCTION}

The last phase in the research process is the publication of research findings in specialised scientific journals. The entire research study is synthesised in a paper, in which all of the pivotal scientific information should be reported clearly for the readers. ${ }^{1}$ Authors who contributed to the developed work are reported in the manuscript. Their position on the list of authors is normally related to their level of contribution to the research project ${ }^{2}$ (eg, the author who contributed the most normally signs as the first author of the paper).

Some rules for the reporting of authorship and contributorship in papers have been suggested by various committees and organisations of journal editors. For instance, the International Committee of Medical Journal Editors (ICMJE) recommends criteria for reporting the contribution of researchers involved in a study.

'Department of Prosthodontics, Dental School, University of Heidelberg, Im Neuenheimer Feld 400, 69120 Heidelberg, Germany

Correspondence to: Dr Clovis Mariano Faggion Jr Email: clovisfaggion@yahoo.com

Refereed Paper

Accepted 22 July 2011

DOI: 10.1038/sj.bdj.2011.721

${ }^{\circledR}$ British Dental Journal 2011; 211: 223-227
These criteria describe, in detail and with examples, who should sign as a co-author or contributor of the research. Other medical journals propose that a description be provided in the paper about the contribution performed by each person listed as a co-author. ${ }^{3}$ The purpose of this description is to improve transparency in the reporting of this authorship/contributorship; the reported authorship contribution information will inform readers about the magnitude of participation of each co-author. Other journals limit the number of authors, aiming to eliminate gratuitous authorship. ${ }^{4}$ However, the policies of dental journals for monitoring authorship and contributorship have not been reported in the literature.

The objective of the present survey was to assess, with specific criteria, the current policies for reporting and monitoring authorship and contributorship of impact factor-ranked dental journals.

\section{METHODOLOGY}

\section{Dental journals search}

The 64 impact factor-ranked dental journals (Journal Citation Reports, Thomson Scientific, Philadelphia, PA, USA; 2009) had their homepages checked between 5 May and 9 May 2011. Specific information related to authorship/contributorship was obtained from the Author Instructions sections.

\section{Criteria for the assessment} of the journals

A modified methodology proposed by Resnik and Master ${ }^{5}$ was used to assess the policies of dental journals regarding authorship/contributorship:

1. Direct link to ICMJE guidelines - Does the journal provide a direct link to the full instructions of ICMJE guidelines (which were the background used to elaborate the present assessment criteria items)?

\section{Contributions that merit authorship}

- Do the instructions provided by the journal describe the contributions necessary to merit authorship, eg, research design, data collection, major conceptual revisions, etc?

3. Contributions that do not merit authorship but merit an acknowledgement - Do the instructions describe the contributions that are insufficient for authorship but sufficient for an acknowledgement, eg, individuals that purely provided technical help, writing assistance, or a department chairperson who provided only general support? 
Table 1 Topics assessed directly in the author instructions section of dental journals

\begin{tabular}{|c|c|c|c|c|c|c|c|}
\hline Dental journal & $\begin{array}{l}\text { Direct link } \\
\text { to ICMJE } \\
\text { guidelines?B }\end{array}$ & $\begin{array}{l}\text { Merit } \\
\text { authorship? }\end{array}$ & $\begin{array}{l}\text { Do not merit } \\
\text { authorship } \\
\text { but merit an } \\
\text { acknowledgement? }\end{array}$ & $\begin{array}{l}\text { Do authors } \\
\text { need to describe } \\
\text { contributions? }\end{array}$ & $\begin{array}{l}\text { Limited } \\
\text { number of } \\
\text { authors? }\end{array}$ & $\begin{array}{l}\text { Do authors } \\
\text { need to take } \\
\text { responsibilities? }\end{array}$ & Score \\
\hline Journal of Clinical Periodontology & $\mathrm{N}$ & Y & $Y^{*}$ & $N$ & N & $N$ & 2 \\
\hline Journal of Dental Research & Y & $N$ & Y & $\mathrm{N}$ & Y & $N$ & 3 \\
\hline Oral Oncology & $\mathrm{N}$ & $\mathrm{N}$ & $\mathrm{N}$ & Y & $N$ & $\mathrm{~N}$ & 1 \\
\hline Periodontology 2000 & $\mathrm{~N}$ & $Y^{*}$ & $Y^{*}$ & $N$ & $N$ & $N$ & 2 \\
\hline Journal of Endodontics & YEt & $\mathrm{N}$ & N & $N$ & $\mathrm{~N}$ & $N$ & 1 \\
\hline Clinical Oral Implants Research & $\mathrm{N}$ & Y & Y & $N$ & Y & $N$ & 3 \\
\hline Dental Materials & $\mathrm{N}$ & $\mathrm{N}$ & $\mathrm{N}$ & $\mathrm{N}$ & N & $\mathrm{N}$ & 0 \\
\hline Caries Research & $\mathrm{N}$ & N & Y & $N$ & N & $\mathrm{N}$ & 1 \\
\hline $\begin{array}{l}\text { Clinical Implant Dentistry } \\
\text { and Related Research }\end{array}$ & $\mathrm{N}$ & N & N & N & $\mathrm{N}$ & $\mathrm{N}$ & 0 \\
\hline $\begin{array}{l}\text { Community Dentistry } \\
\text { and Oral Epidemiology }\end{array}$ & N & Y & $Y^{*}$ & N & N & N & 2 \\
\hline $\begin{array}{l}\text { Oral Microbiology and Immunology } \\
\text { (Molecular Oral Microbiology) }\end{array}$ & N & $Y^{*}$ & $Y^{*}$ & $\mathrm{~N}$ & N & $\mathrm{N}$ & 2 \\
\hline Clinical Oral Investigations & $\mathrm{N}$ & N & $\mathrm{N}$ & N & N & $\mathrm{N}$ & 0 \\
\hline International Endodontic Journal & $\mathrm{N}$ & Y & $Y^{*}$ & $\mathrm{~N}$ & N & $\mathrm{N}$ & 2 \\
\hline Journal of Periodontology & $\mathrm{N}$ & Y & Y & $\mathrm{N}$ & $\mathrm{N}$ & $\mathrm{N}$ & 2 \\
\hline Journal of Oral Pathology and Medicine & $\mathrm{N}$ & Y & $Y^{*}$ & $\mathrm{~N}$ & $N$ & N & 2 \\
\hline Journal of Dentistry & $\mathrm{N}$ & $Y^{*} \#$ & $\mathrm{~N}$ & $N$ & $N$ & $N$ & 1 \\
\hline $\begin{array}{l}\text { The International Journal of Oral } \\
\text { and Maxillofacial Implants }\end{array}$ & $\mathrm{N}$ & $Y^{\wedge} \#$ & $\mathrm{~N}$ & $\mathrm{~N}$ & $\mathrm{~N}$ & $\mathrm{Y}$ & 2 \\
\hline Journal of Periodontal Research & N & Y & $Y^{*}$ & $\mathrm{~N}$ & N & $\mathrm{N}$ & 2 \\
\hline European Journal of Oral Sciences & $\mathrm{N}$ & Y & Y & $\mathrm{N}$ & $N$ & $\mathrm{~N}$ & 2 \\
\hline Oral Diseases & $\mathrm{N}$ & Y & Y & Y\% & N & $\mathrm{N}$ & 3 \\
\hline $\begin{array}{l}\text { The Journal of the American } \\
\text { Dental Association }\end{array}$ & $N$ & $Y^{*}$ & $\mathrm{~N}$ & Y\% & N & $\mathrm{N}$ & 2 \\
\hline $\begin{array}{l}\text { The International Journal of } \\
\text { Periodontics and Restorative Dentistry }\end{array}$ & $\mathrm{N}$ & $Y^{\wedge} \#$ & $\mathrm{~N}$ & $\mathrm{~N}$ & $N$ & Y & 2 \\
\hline Operative Dentistry & $\mathrm{N}$ & $\mathrm{N}$ & $\mathrm{N}$ & $\mathrm{N}$ & N & $\mathrm{N}$ & 0 \\
\hline Archives of Oral Biology & $\mathrm{N}$ & Y & Y & N & N & N & 2 \\
\hline The Journal of Adhesive Dentistry & $\mathrm{N}$ & $\mathrm{N}$ & $Y^{*}$ & $\mathrm{~N}$ & N & $\mathrm{N}$ & 1 \\
\hline Orthodontics and Craniofacial Research & $\mathrm{N}$ & Y & $Y^{*}$ & N & $\mathrm{N}$ & $\mathrm{N}$ & 2 \\
\hline Journal of Oral and Maxillofacial Surgery & $\mathrm{N}$ & N & $Y^{*}$ & $N$ & $\mathrm{~N}$ & $\mathrm{~N}$ & 1 \\
\hline Implant Dentistry & $\mathrm{N}$ & $\mathrm{N}$ & $\mathrm{N}$ & $\mathrm{N}$ & $N$ & $\mathrm{~N}$ & 0 \\
\hline $\begin{array}{l}\text { Oral Surgery Oral Medicine Oral Pathology } \\
\text { Oral Radiology and Endodontology }\end{array}$ & $\mathrm{N}$ & Y & $Y^{*}$ & $\mathrm{~N}$ & N & $\mathrm{N}$ & 2 \\
\hline Journal of Oral Rehabilitation & $\mathrm{N}$ & Y & $Y^{*}$ & $\mathrm{~N}$ & $\mathrm{~N}$ & $\mathrm{~N}$ & 2 \\
\hline $\begin{array}{l}\text { International Journal of Oral } \\
\text { and Maxillofacial Surgery }\end{array}$ & $\mathrm{N}$ & Y & Y & $\mathrm{N}$ & $Y \Phi$ & $\mathrm{Y}$ & 4 \\
\hline Acta Odontologica Scandinavica & $\mathrm{N}$ & $\mathrm{N}$ & $\mathrm{N}$ & Y\% & $N$ & $\mathrm{~N}$ & 1 \\
\hline $\begin{array}{l}\text { American Journal of Orthodontics } \\
\text { and Dentofacial Orthopedics }\end{array}$ & $\mathrm{N}$ & $\mathrm{N}$ & $\mathrm{N}$ & $\mathrm{N}$ & $\mathrm{N}$ & $\mathrm{Y}$ & 1 \\
\hline $\begin{array}{l}\text { British Journal of Oral and } \\
\text { Maxillofacial Surgery }\end{array}$ & N & Y & Y & $\mathrm{N}$ & $\mathrm{Yq}$ & $\mathrm{N}$ & 3 \\
\hline Dental Traumatology & $\mathrm{N}$ & Y & $Y^{*}$ & $N$ & $\mathrm{~N}$ & $N$ & 2 \\
\hline American Journal of Dentistry & $\mathrm{N}$ & $\mathrm{N}$ & $\mathrm{N}$ & N & $N$ & N & 0 \\
\hline Journal of Orofacial Pain & $\mathrm{N}$ & $Y^{\wedge} \#$ & $Y^{*}$ & $\mathrm{~N}$ & $\mathrm{~N}$ & Y & 3 \\
\hline Journal of Cranio-Maxillo-Facial Surgery & $\mathrm{N}$ & Y & Y & N & N & N & 2 \\
\hline Dento Maxillo Facial Radiology & $\mathrm{N}$ & $\mathrm{N}$ & $\mathrm{N}$ & $\mathrm{N}$ & $N$ & $\mathrm{Y}$ & 1 \\
\hline $\begin{array}{l}\text { The International Journal } \\
\text { of Prosthodontics? }\end{array}$ & N & $\mathrm{N}$ & $Y^{*}$ & $\mathrm{~N}$ & N & N & 1 \\
\hline Australian Dental Journal & $\mathrm{N}$ & $Y^{*}$ & $Y^{*}$ & $\mathrm{~N}$ & $N$ & Y & 3 \\
\hline
\end{tabular}


Table 1 Topics assessed directly in the author instructions section of dental journals

\begin{tabular}{|c|c|c|c|c|c|c|c|}
\hline Dental journal & $\begin{array}{l}\text { Direct link } \\
\text { to ICMJE } \\
\text { guidelines?B }\end{array}$ & $\begin{array}{l}\text { Merit } \\
\text { authorship? }\end{array}$ & $\begin{array}{l}\text { Do not merit } \\
\text { authorship } \\
\text { but merit an } \\
\text { acknowledgement? }\end{array}$ & $\begin{array}{l}\text { Do authors } \\
\text { need to describe } \\
\text { contributions? }\end{array}$ & $\begin{array}{l}\text { Limited } \\
\text { number of } \\
\text { authors? }\end{array}$ & $\begin{array}{l}\text { Do authors } \\
\text { need to take } \\
\text { responsibilities? }\end{array}$ & Score \\
\hline \multicolumn{8}{|c|}{ Continued from page 224} \\
\hline The Journal of Prosthetic Dentistry & $\mathrm{N}$ & $\mathrm{N}$ & $Y^{*}$ & Y\% & Y & N & 3 \\
\hline $\begin{array}{l}\text { International Journal } \\
\text { of Paediatric Dentistry }\end{array}$ & $N$ & Y & $Y^{*}$ & $\mathrm{~N}$ & $\mathrm{~N}$ & N & 2 \\
\hline British Dental Journal & $\mathrm{N}$ & $\mathrm{N}$ & $\mathrm{N}$ & $\mathrm{N}$ & $\mathrm{N}$ & N & 0 \\
\hline Journal of Dental Education & $\mathrm{N}$ & $\mathrm{N}$ & $\mathrm{N}$ & $\mathrm{N}$ & N & N & 0 \\
\hline European Journal of Dental Education & $\mathrm{N}$ & Y & $Y^{*}$ & N & $\mathrm{N}$ & N & 2 \\
\hline Gerodontology & $\mathrm{N}$ & Y & $Y^{*}$ & N & $\mathrm{N}$ & N & 2 \\
\hline European Journal of Orthodontics & $\mathrm{N}$ & Y & $\mathrm{N}$ & N & N & N & 1 \\
\hline Community Dental Health & $\mathrm{N}$ & $\mathrm{N}$ & $\mathrm{N}$ & N & N & N & 0 \\
\hline Journal of Public Health Dentistry & $\mathrm{N}$ & Y & $Y^{*}$ & $\mathrm{~N}$ & $\mathrm{~N}$ & N & 2 \\
\hline $\begin{array}{l}\text { Journal of the Canadian } \\
\text { Dental Association }\end{array}$ & $\mathrm{N}$ & $\mathrm{N}$ & $Y^{*}$ & $\mathrm{~N}$ & $\mathrm{~N}$ & $\mathrm{~N}$ & 1 \\
\hline Angle Orthodontist & $\mathrm{N}$ & $\mathrm{N}$ & $\mathrm{N}$ & N & $\mathrm{N}$ & N & 0 \\
\hline \multicolumn{8}{|l|}{ Dental Materials Journalß } \\
\hline Swedish Dental Journal & N & N & $\mathrm{N}$ & N & $\mathrm{N}$ & N & 0 \\
\hline Journal of Orofacial Orthopedics & N & $\mathrm{N}$ & $\mathrm{N}$ & $\mathrm{N}$ & $\mathrm{N}$ & N & 0 \\
\hline Cleft Palate-Craniofacial Journal & N & Y & N & $\mathrm{N}$ & N & Y & 2 \\
\hline $\begin{array}{l}\text { Journal of Esthetic } \\
\text { and Restorative Dentistry }\end{array}$ & N & $\mathrm{N}$ & Y & N & N & N & 1 \\
\hline Odontology & $\mathrm{N}$ & $\mathrm{N}$ & $\mathrm{N}$ & $\mathrm{N}$ & $\mathrm{N}$ & N & 0 \\
\hline Quintessence International & $\mathrm{N}$ & $Y^{\wedge} \#$ & $\mathrm{~N}$ & N & N & Y & 2 \\
\hline International Dental Journal & $\mathrm{N}$ & Y & Y & $\mathrm{N}$ & Y & N & 3 \\
\hline Journal of Cranio-Mandibular Practice & $\mathrm{N}$ & $\mathrm{N}$ & $\mathrm{N}$ & $\mathrm{N}$ & $\mathrm{N}$ & N & 0 \\
\hline Journal of Applied Oral Science & $\mathrm{N}$ & $\mathrm{N}$ & $\mathrm{N}$ & $\mathrm{N}$ & $\mathrm{N}$ & Y & 1 \\
\hline \multicolumn{8}{|l|}{$\begin{array}{l}\text { Revue de Stomatologie et de } \\
\text { Chirurgie Maxillo-Faciale } \Omega\end{array}$} \\
\hline Journal of Dental Sciences & $\mathrm{N}$ & $\mathrm{N}$ & Y & $\mathrm{N}$ & $\mathrm{N}$ & $\mathrm{N}$ & 1 \\
\hline \multicolumn{8}{|c|}{ 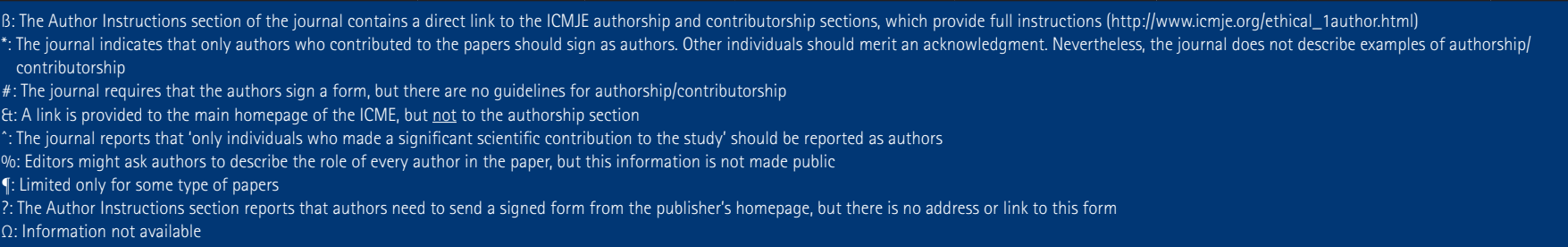 } \\
\hline
\end{tabular}

\section{Descriptions of each author's} contributions - Do the instructions indicate that all of the authors should describe their contributions either directly in the prepared manuscript or in a note provided to the journal?

5. Limited number of authors - Do the instructions provide a maximum number of authors allowed to sign the paper, or is there a specific policy for multiple authors/research groups?

6. Taking responsibility for the manuscript (in whole or part) - Do the instructions indicate that all authors should take responsibility for just their contributions or for the entire manuscript?

This 6-item form was used to extract and record information. Only information that was explicitly reported in the Author Instructions section was retrieved. The rationale was to assess the level of information that is made publically available to the interested reader. The emphasis of the 6-item list was on clear reporting; for example, we assessed whether the journal provided examples with its authorship/contributorship guidelines. To increase the reliability of the assessment, the information was performed twice on two different occasions (5 May and 9 May 2011).

Items were scored as yes when the information was explicitly described in the Author Instructions section; otherwise, the item was scored as no. Results are descriptively reported in a table format and, when necessary, the assessment rationale is explained in a footnote (Table 1).

\section{RESULTS}

A total of 62 impact factor-ranked dental journals were assessed (Table 1, Fig. 1). In the case of two journals, the Author Instructions sections were not available for assessment. Only two journals had a 
direct link to the ICMJE authorship guidelines (one journal had a direct link to the ICMJE main page). A total of 30 journals ( $48 \%$ of the assessed sample) reported that only individuals who actively contributed to the research should sign as authors, whereas nine journals (15\% of the sample) did not describe the requirements for authorship. The number of journals that did not provide guidelines explaining the requirements for signing as a contributor in the acknowledgments sections was even higher (22 journals, 35\%).

One journal required that the contributions by authors be detailed in a signed form, and four journals indicated that the editor might ask the authors to describe the role of every author in the paper. Nevertheless, none of these five journals made this information available to the public, as confirmed by an assessment of the full-text of papers published by the journals.

Six journals (10\% of the sample) limited the number of authors or had specific policies for multiple authors/research groups. Two journals limited the number of authors only for some types of study designs.

\section{DISCUSSION}

Policies for monitoring authorship/contributorship and other measures, such as monitoring conflicts of interest ${ }^{6}$ and publication of original ('raw') data ${ }^{7}$ with the submitted manuscript, are strategies that aim to improve transparency and public trust in dental research. The main objective of this survey was to assess the strategies and standards by which highranked dental journals report their policies for monitoring authorship. The presented data demonstrate that there is room for improvement in the reporting of this information. Clear rules for authorship are necessary to reduce cases of 'guest authors' ${ }^{8}$ (who sign as authors without meeting authorship criteria) and 'ghost authors'9 (who are credited to get an authorship, but for some reason do not sign the article).

Very few dental journals provide a direct link to the ICMJE authorship guidelines on their homepages. Inclusion of these guidelines could easily improve the accuracy, equity, and transparency of policies on authorship, ${ }^{10}$ by informing authors of the requirements for manuscript submission (the ICMJE guidelines, with definitions

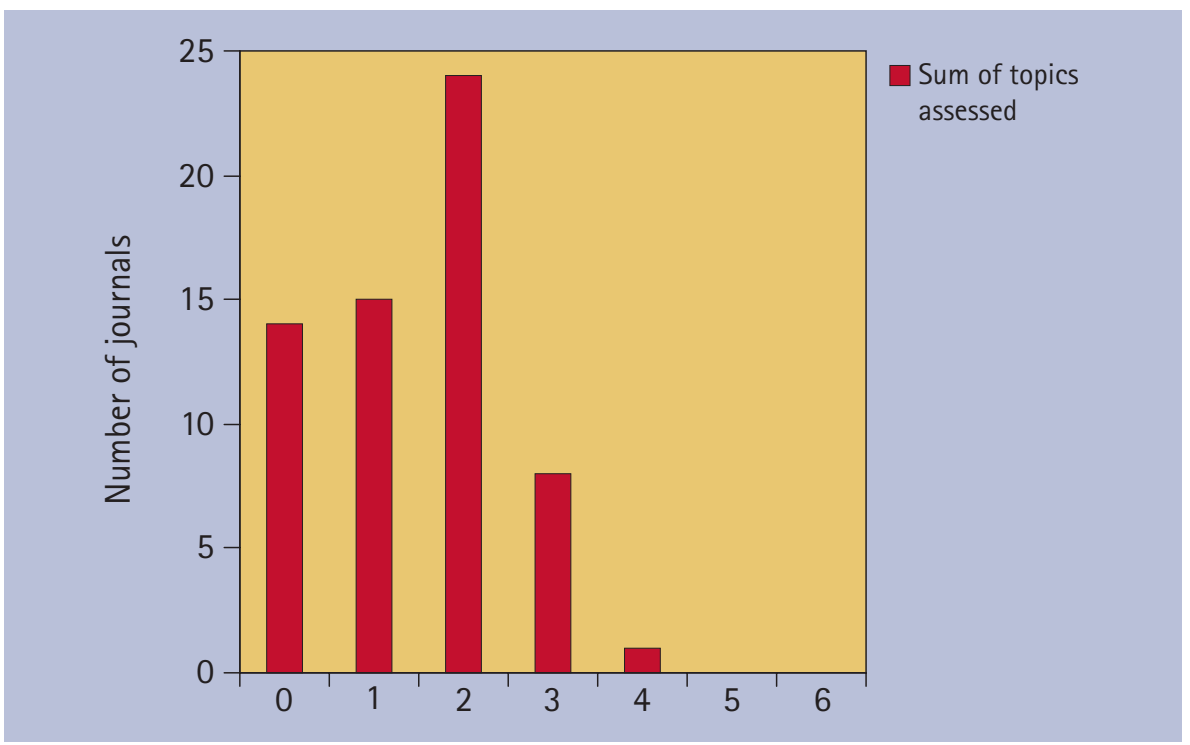

Fig. $1 \mathrm{X}$-axis shows the score sums of topics assessed from the Authors Instructions of the examined dental journals. $Y$-axis is the number of journals that correspond to each score sum

Table 2 ICMJE guidelines for authorship/contributorship

\section{Authorship}

- Authorship credit should be based on 1) substantial contributions to conception and design, acquisition of data, or analysis and interpretation of data; 2 ) drafting the article or revising it critically for important intellectual content; and 3) final approval of the version to be published. Authors should meet conditions 1, 2, and 3 .

- When a large, multicentre group has conducted the work, the group should identify the individuals who accept direct responsibility for the manuscript. These individuals should fully meet the criteria for authorship/contributorship defined above, and editors will ask these individuals to complete journal-specific author and conflict-of-interest disclosure forms. When submitting a manuscript authored by a group, the corresponding author should clearly indicate the preferred citation and identify all individual authors as well as the group name. Journals generally list other members of the group in the Acknowledgments. The NLM indexes the group name and the names of individuals the group has identified as being directly responsible for the manuscript; it also lists the names of collaborators if they are listed in Acknowledgments.

- Acquisition of funding, collection of data, or general supervision of the research group alone does not constitute authorship.

- All persons designated as authors should qualify for authorship, and all those who qualify should be listed.

- Each author should have participated sufficiently in the work to take public responsibility for appropriate portions of the content.

\section{Contributorship}

- All contributors who do not meet the criteria for authorship should be listed in an acknowledgments section. Examples of those who might be acknowledged include a person who provided purely technical help, writing assistance, or a department chairperson who provided only general support. Editors should ask corresponding authors to declare whether they had assistance with study design, data collection, data analysis, or manuscript preparation. If such assistance was available, the authors should disclose the identity of the individuals who provided this assistance and the entity that supported it in the published article. Financial and material support should also be acknowledged.

- Groups of persons who have contributed materially to the paper but whose contributions do not justify authorship may be listed under such headings as 'clinical investigators' or 'participating investigators', and their function or contribution should be described-for example, 'served as scientific advisors', 'critically reviewed the study proposal', 'collected data', or 'provided and cared for study patients'. Because readers may infer their endorsement of the data and conclusions, these persons must give written permission to be acknowledged.

of authorship and contributorship, are described in Table 2). Many dental journals partially report these requirements; for example, some only recommend that 'authors who have not actively contributed to the paper' should sign as a contributor in the acknowledgements section. Nevertheless, the provision of nonspecific information without any examples can confuse readers and is open to diverse interpretations.

Unlike some high-ranked medical journals, ${ }^{3}$ dental journals do not make publicly 
available the contribution of each author/ contributor in a published paper. This policy might be relevant for two main reasons. First, it might provide information that could enable reviewers and editors to monitor the specific work performed by any contributor. Second, if peer-reviewing editors, reviewers, or interested readers want to obtain precise information about a specific section of the paper, author contribution information provides the information that they need to identify who they should contact. For example, if an editor or reader has a statistical question, then he or she can directly contact the author responsible for the statistical assessment of the study. Nevertheless, some recent reports suggest that author contribution disclosures might not be effective in reducing or controlling the number of authors that sign a paper. ${ }^{3,4}$ In fact, the number of authors per paper has increased in recent years. ${ }^{11-14}$ Possible explanations for this phenomenon may include the need for publishing, increased research complexity (mainly in the area of clinical trials, where several centres may be involved), and inappropriate authorship. ${ }^{13}$

Inappropriate authorship may occur in different situations, such as when chairmen systematically sign as the last author or at any intermediate position in the papers of their subordinate researchers. ${ }^{15}$ According to the ICMJE guidelines, to sign as an author, the chairmen or research supervisors should actively participate in the research development and experimentation. Nevertheless, it is often difficult to quantify the magnitude of the participation of the chairmen and research supervisors in the project. Similarly, researchers may form teams to conduct different projects, and they may exchange positions on the many papers derived from these projects to improve their overall publication performance. In this scenario, the level of participation of the investigators in the project is unclear to the reader and editors.

Similar to guest authors, the existence of ghost authors is also a reality. A recent study found a great prevalence of ghost authorship in industry-initiated randomised trials. ${ }^{9}$ This phenomenon might be related to commercial purposes. ${ }^{9,16}$ Although contribution disclosure may not necessarily be an effective strategy for reducing the number of guest authors, detailed disclosure on authorship/contributions might be effective in monitoring ghost authorship.

The argument could be made that assessing the policies of journals from the Author Instructions sections may not be precise, because information that is lacking might be available in a later stage of the submission process. ${ }^{17}$ Nevertheless, the reader is the obvious target of dental journals; a clear report of these polices should be provided without needing to log into the paper submission process to obtain detailed further information.

In conclusion, the present survey demonstrates that detailed information on authorship/contributorship is not publicly available for high-ranked dental journals. Editors and journal board members should consider making alterations to this reporting to improve author adherence to established guidelines and to promote a more efficient research process.
1. Schulz K F, Altman D G, Moher D; CONSORT Group. CONSORT 2010 statement: updated guidelines for reporting parallel group randomised trials. BMJ 2010; 340: c332.

2. Wren J D, Kozak K Z, Johnson K R, Deakyne S J, Schilling L M, Dellavalle R P. The write position. A survey of perceived contributions to papers based on byline position and number of authors. EMBO Rep 2007; 8: 988-991.

3. Baerlocher M 0, Gautam T, Newton M, Tomlinson G. Changing author counts in five major general medicine journals: effect of author contribution forms. J Clin Epidemio/ 2009; 62: 875-877.

4. McDonald R J, Neff K L, Rethlefsen M L, Kallmes D F. Effects of author contribution disclosures and numeric limitations on authorship trends. Mayo Clin Proc 2010; 85: 920-927.

5. Resnik D B, Master Z. Authorship policies of bioethics journals. J Med Ethics 2011; 37: 424-428.

6. Drazen J M, de Leeuw P W, Laine $C$ et al. Toward more uniform conflict disclosures: the updated ICMJE conflict of interest reporting form. JAMA 2010; 304: 212-213.

7. Vickers A J. Whose data set is it anyway? Sharing raw data from randomized trials. Trials 2006; 7: 15

8. Ross J S, Hill K P, Egilman D S, Krumholz H M. Guest authorship and ghostwriting in publications related to rofecoxib: a case study of industry documents from rofecoxib litigation. JAMA 2008; 299: 1800-1812.

9. Gøtzsche P C, Hróbjartsson A, Johansen H K, Haahr M T, Altman D G, Chan A W. Ghost authorship in industry-initiated randomised trials. PLoS Med 2007; 4: e19.

10. Wager E. Do medical journals provide clear and consistent guidelines on authorship? MedGenMed 2007; 9: 16 .

11. Glynn R W, Kerin M J, Sweeney KJ. Authorship trends in the surgical literature. Br J Surg 2010; 97: 1304-1308.

12. Yuan J C, Lee D J, Knoernschild K L, Campbell S D, Sukotjo C. Authorship characteristics in prosthodontic literature: proliferation and internationalization. A review and analysis following a 10-year observation. J Prosthet Dent 2010; 104: 158-164.

13. Dotson B, McManus K P, Zhao J J, Whittaker P. Authorship and characteristics of articles in pharmacy journals: changes over a 20-year interval. Ann Pharmacother 2011; 45: 357-363.

14. Barão V A, Shyamsunder N, Yuan J C, Lee D J, Assunção W G, Sukotjo C. Authorship, collaboration, and funding trends in implantology literature: analysis of five journals from 2005 to 2009. Implant Dent 2011; 20: 68-75.

15. Drenth J P. Multiple authorship: the contribution of senior authors. JAMA 1998; 280: 219-221.

16. Steinman M A, Bero L A, Chren M M, Landefeld C S. Narrative review: the promotion of gabapentin: an analysis of internal industry documents. Ann Intern Med 2006; 145: 284-293.

17. Schuklenk U. Bioethics authorship guidelines. J Med Ethics 2011; 37: 449. 